\title{
Pelos campos da comunicação - Edição Especial
}

Em seu quinto número, RuMoRes apresenta uma edição especial: reunindo doze artigos de alunos de mestrado e doutorado do Programa de Pós-Graduação em Ciências da Comunicação da Escola de Comunicações e Artes da Universidade de São Paulo (PPGCOM-USP), podemos perceber um conjunto de temáticas relativas a diversas abordagens nos estudos de comunicação. Articulando as linhas de pesquisa do Programa, temos textos que tratam de questões teóricas, metodológicas e epistemológicas; textos que abordam processos e produtos das mídias impressa, audiovisual e digital; e aqueles que abordam a comunicação em suas interfaces sociais.

Os textos aqui reunidos foram selecionados entre os trabalhos apresentados na I Jornada Acadêmica do PPGCOM-USP, realizada em 24 de outubro de 2008, em que alunos e alunas de pós-graduação estiveram reunidos para apresentar as pesquisas que vêm desenvolvendo. O evento teve como objetivo integrar e promover o intercâmbio científico e cultural da comunidade acadêmica da ECA. Em forma de seminário, a Jornada Acadêmica contou com apresentações e discussões de trabalhos de pesquisa realizados pelo corpo discente do Programa, permitindo a divulgação e troca de informações e experiências relacionadas à prática de pesquisa em Comunicação.

Sob a coordenação de professores do Programa, tivemos a apresentação de doze mesas temáticas compostas por pelo menos quatro alunos e alunas, totalizando a participação de 49 discentes. Os temas trataram de questões sobre linguagem, mídias digitais, metodologia, teoria da comunicação, audiovisual, comunicação organizacional, educomunicação, questões sociais, recepção e produção de sentido nas mídias, entre outros. Além das apresentações, tivemos a presença de participantes ouvintes; todos os inscritos receberam certificados pela atividade realizada e os trabalhos apresentados foram publicados na íntegra em forma de anais eletrônicos. Os resumos das apresentações, a programação e os textos completos encontram-se no site http://www.jornadappgcom.rg3.net.

Dentre os trabalhos apresentados, selecionamos os mais representativos em mídia impressa, tratando de publicidade e jornalismo; nos estudos de audiovisual, incluindo televisão, cinema e filmes documentários; no campo referente às mídias digitais, com temáticas relativas à colaboração, interatividade a autoria; e nas relações teóricas sobre linguagem, imagens e comunicação.

No campo das mídias digitais, o primeiro artigo, de Hernani Dimantas, aborda a apropriação da tecnologia social e suas formas de intervenção na realidade brasileira por meio do estudo da lista de discussão Metá:Fora, criada para debater a inclusão social. Na seqüência, Beatriz Cintra Martins analisa a publicação eletrônica Overmundo tendo como referencial teórico a semiótica da cultura, especialmente em relação à autoria coletiva praticada neste website, constituindo uma ação coletiva dialógica em um espaço público virtual. Luci Ferraz de Melo, em seu texto, reflete sobre a correlação entre o surgimento das tecnologias digitais, a evolução do conceito de interatividade e dialogicidade, e as conseqüentes transformações nos processos de ensino-aprendizagem.

Em relação às mídias impressas, três artigos compõem um quadro relativo aos seus modos de produção e recepção a partir de diferentes pontos de vista. No texto de Renata Carvalho da Costa, temos uma aproximação às formas de produção do jornalismo e da literatura por meio da análise de processos de edição de livros e em jornalismo impresso. Sob uma perspectiva contrastiva, Cristina Miyuki Sato apresenta as diferentes estratégias cognitivas utilizadas por redatores e leitores da tradicional imprensa para comunidades estrangeiras no Brasil, em especial a nipo-brasileira, para se relacionarem com os textos dessas publicações, apontando para as formas de construção de identidades promovidas por essas publicações. Carlos Augusto de 
Miranda e Martins, por sua vez, apresenta em seu artigo a origem histórica da baixa participação do negro nas mídias e sua constante representação estereotipada, em especial na publicidade, discutindo aspectos quantitativos relativos à presença do negro em anúncios comerciais.

Os estudos de meios e processos audiovisuais trazem como colaboração os textos de Alzimar Rodrigues Ramalho, Priscila de Almeida Xavier e Maurício Cândido Taveira. O primeiro artigo aborda a necessidade de institucionalização dos canais de televisão universitários para que possam se consolidar como mídias representativas da sociedade, refletindo sobre as relações entre a universidade enquanto produtora de conhecimento científico e a televisão enquanto mídia educativa. No segundo artigo, temos uma discussão sobre os tipos de análise que podem ser ponderadas para o campo do cinema documentário, considerando também a questão dos gêneros institucional, científico e didático. A partir da representação que uma instituição de pesquisa científica faz de si, através do cinema, é analisado um filme produzido na década de 50 pelo Instituto Butantan, de São Paulo. Ainda no campo do audiovisual, o terceiro texto propõe uma reflexão sobre os impactos que a mídia dvd vem engendrando na linguagem cinematográfica, especialmente por suas possibilidades de intervenção por parte do espectador, a partir da comparação entre os filmes "Smoking" e "No Smoking", de Alain Resnais, e o dvd interativo "Play Smoking/No Smoking", criado pelo autor do artigo.

Finalmente, os três últimos artigos dessa edição abordam questões teóricas relativas ao campo da comunicação, sobretudo na interface entre linguagem e imagem. O texto de Andrea Limberto Leite apresenta os processos de censura prévia ao teatro do Arquivo Miroel Silveira, analisando o caso da comédia "Cidadão Zero", de Gastão Pereira da Silva, a partir da retórica das figuras e da análise de discurso, tomando-as como forma de produção de sentido e possibilidade de sustentar uma formação ideológica e estereotípica. Uma reflexão sobre o conceito de comunicação popular como forma de contribuir para a construção da cidadania na comunidade, a partir do conhecimento de direitos e deveres, é o que lemos no texto de Cristiane Reimberg. $\mathrm{O}$ artigo também trata de como essa comunicação, que valoriza a comunidade, pode acontecer em uma sociedade de massa, estabelecendo relações com o jornalismo. Finalmente, o artigo de Rafael Elias Teixeira traz alguns apontamentos iniciais sobre a investigação da relação entre as imagens produzidas por meio de aparatos tecnológicos e a construção da realidade na contemporaneidade, considerando-os como marca de uma mudança profunda nos processos humanos de cognição e percepção do mundo na sociedade tecnológica.

Esperamos que esta edição especial de RuMoRes possa trazer aos leitores não apenas uma possibilidade de conhecer alguns dos eixos e temáticas dos estudos realizados na ECA-USP, mas também a oportunidade de estabelecer um debate produtivo sobre as tendências contemporâneas da pesquisa em comunicação. Boa leitura!

Rosana de Lima Soares 